\title{
Reinforcing concrete shells with cement composite stay-in-place formwork: numerical analysis of a case study
}

\author{
E. Verwimp ${ }^{1,2}$, T. Tysmans ${ }^{1} \&$ M. Mollaert ${ }^{2}$ \\ ${ }^{1}$ Department of Mechanics of Materials and Constructions (MeMC), Vrije \\ Universiteit Brussel, Belgium \\ ${ }^{2}$ Department of Architectural Engineering (ARCH), Vrije Universiteit \\ Brussel, Belgium
}

\begin{abstract}
This paper describes a new method for constructing concrete shells using textile reinforced cement (TRC) composites as flexible formwork and tensile reinforcement. By means of a case study on a synclastic concrete shell, which is a compression-only structure under its self weight, the paper presents the analysis of the TRC formwork on the one hand and the TRC reinforcement on the other hand. The analysis of the formwork and the reinforcement is performed using the finite element software Abaqus. For this synclastic shell, the formwork stage is the deciding stage. Local buckling of the edges of the shell's formwork is the determining factor for the TRC thickness. For this reason, special attention is paid to these edges and to solutions which decrease the needed TRC thickness.

Keywords: textile reinforced cement composite, flexible formwork, synclastic shell.
\end{abstract}

\section{Introduction}

The construction of concrete shells is a challenge in western regions. Firstly, the current formwork methods are labour intensive or material wasting. The two main methods are timber moulds and foam blocks. Timber moulds are only effective when low curvature is wanted because it is complex to obtain curved surfaces and therefore very time consuming (Weilandt [1]). With foam blocks every shape can be milled, but due to concrete residues after hardening the blocks are wasted (Nedcam [2]). A second issue obstructing the construction of concrete shells is the 
tensile reinforcement. Reinforcement is needed in structural concrete elements, but the inflexibility of traditional steel reinforcement practically limits the curvature of shells. Moreover, the steel reinforcement requires a minimal concrete cover against corrosion, what means that this cover determines the minimal thickness of the shell.

There is a need for a new and inventive formwork solution, which provides sufficient flexibility to obtain curved surfaces, has the necessary stiffness in casting stage and moreover fulfills a reinforcing function after hardening of the concrete. To this end, we developed a new method which complies with these criteria by exploiting the properties of textile reinforced cement (TRC) composites.

This paper presents the analysis of a double curved synclastic shell, with a span of $10 \mathrm{~m}$ and a height of 4,8 m. Firstly, the TRC formwork is analysed for this shell and secondly the necessary TRC as reinforcement. From this analysis it is concluded which phase determines the dimensioning of the TRC layer.

\section{TRC composites to construct concrete shells}

The properties of textile reinforced cement composites are presented in the following paragraphs by explaining their prominent role in the new method to construct concrete shells.

Textile reinforced cement (TRC) composites are textiles impregnated with a cement or fine grained mortar, which hardens at ambient temperatures. As long as the cement is wet, the composite provides the flexibility to easily obtain curved shapes (Figure 1).
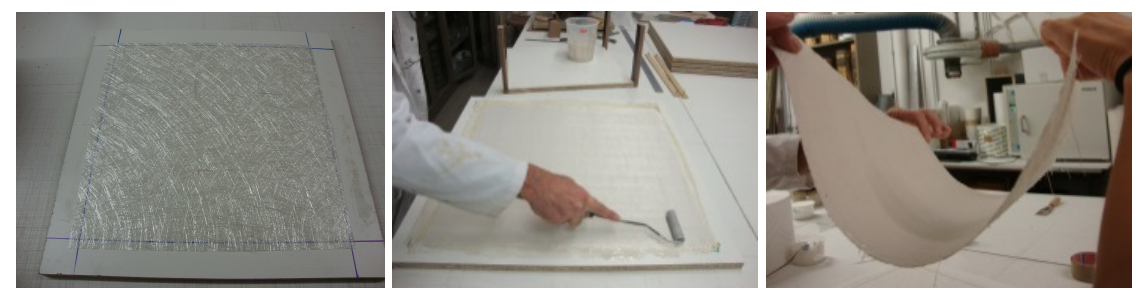

Figure 1: Random glass fibre mats (left) are impregnated with a cement (middle) and as long as the cement is still wet, the composite is flexible (right).

To obtain the curved shapes, the TRC formwork can be shaped onto any (reusable) mould such as foam moulds, pneumatic formwork (Figure 2) etc. The low weight of the TRC layer compared with concrete, which is normally poured on these moulds, is a great advantage. In other words, the TRC gives an added value to these existing moulding systems. The TRC formwork can also be produced as prefab elements, which are connected on site.

When using textiles instead of discontinuous fibres, much higher fibre volume fractions can be achieved than when chopped fibres are mixed into the matrix. 

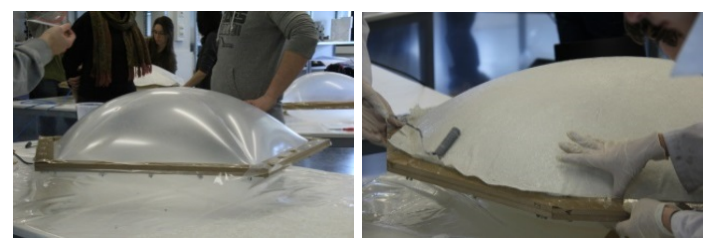

Figure 2: Curved TRC elements are easily made on pneumatic formwork.

Thus, cement composites with good mechanical properties, i.e. high tensile and compressive strength, are obtained. TRC composites show already a non-linear behaviour at low tensile stresses due to the low tensile failure strain of the matrix relative to that of the fibres. However, thanks to high fibre volume fractions the composite can obtain a significant post-cracking stiffness and tensile strength. As Figure 3 shows, a TRC composite with 11 volume \% of random glass fibres mats can resist a stress of $20 \mathrm{MPa}$ at $1 \%$ strain, while increasing the fibre volume fraction to $23 \%$ will approximately triple the tensile failure strength $(60 \mathrm{MPa})$.

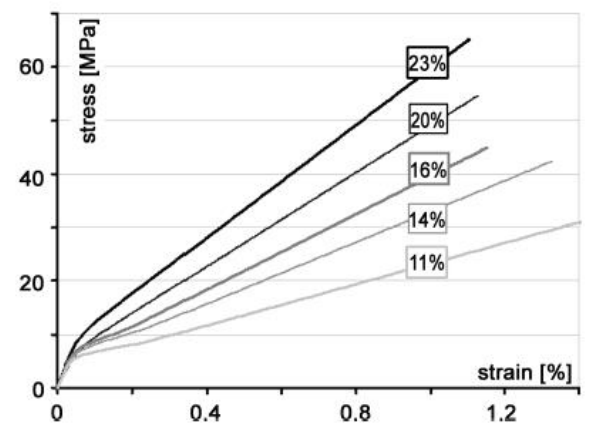

Figure 3: Increasing the fibre volume fraction increases the post-cracking stiffness and tensile strength of a TRC composite (Remy and Wastiels [3]).

In this study the matrix Inorganic Phosphate Cement (IPC), developed at Vrije Universiteit Brussel (EP 0861216 B1 [4]), is used in combination with Eglass fibre textiles. This cement becomes $\mathrm{pH}$-neutral after hardening and does not degrade the glass fibres. It has very small grain sizes, so very good impregnation of the textile is possible and the composite can be produced very thin $(1 \mathrm{~mm})$ (Cuypers and Wastiels [5]). From now on, in all subsequent text, when the term TRC is used, IPC reinforced with random E-glass fibre textiles is intended.

Because of the relatively high mechanical compressive and tensile capacities, TRC in its hardened state is a very suitable material as stay-in-place formwork for concrete shell structures, namely to resist the pressure of the poured wet concrete (Figure 4) and also to act as a (partial) tensile reinforcement of the final concrete structure. 

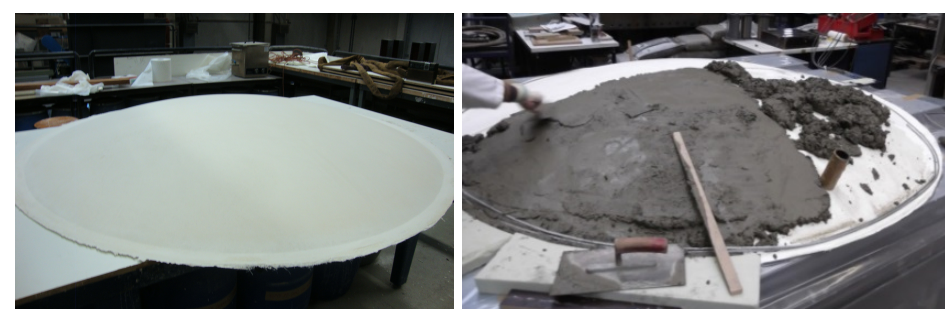

Figure 4: TRC in its hardened phase is suitable as permanent formwork for concrete.

Finally, after hardening of the concrete, a mixed TRC-concrete section is obtained. Due to the relatively good tensile capacities of TRC and the good bonding between TRC and concrete (Remy [6]), we expect a reinforcing action. On top of that, the used TRC is incombustible, which is another advantage of the used material.

\section{Analysis of the synclastic shell}

This section focuses on the structural analysis of TRC formwork and reinforcement. First, it describes the geometry which is examined in this study. Second, it presents the used materials and their mechanical properties. Next, it explains the proposed methodologies for determining the TRC thickness as formwork on the one hand and as reinforcement on the other hand for the synclastic concrete shell and discusses the results with reference to the dominant load cases.

\subsection{Geometry and finite element modelling}

The examined shell shape is a funicular shape under vertical distributed loading. This shape was determined using the form finding software Easy. This software is based on the force density method and searches for the equilibrium shape under a certain load case. In this case study a vertical distributed load of $0,60 \mathrm{kN} / \mathrm{m}^{2}$ was applied to the grid (Figure 5a) to obtain the geometry where the force densities are $1 \mathrm{kN} / \mathrm{m}$ in the membrane and 5,71 kN/m in the boundary cables (Figure 5b). This implies that the boundaries are stiffer. This membrane structure is turned into a continuous surface to obtain the final shell geometry (Figure 5c). The shell covers an area of $10 \mathrm{~m}^{2}$, is $4,8 \mathrm{~m}$ high and is hinged in its four corners. The corners measure $0,8 \mathrm{~m}$ (Figure 5d) to exclude stress concentrations. TRC formwork and reinforcement are analysed for a concrete section of $15 \mathrm{~mm}$.

The shell is analysed in the finite element (FE) software Abaqus, where it is modeled as a shell model with a continuous shell section, where the bond between concrete and the TRC layer is assumed to be perfect. Two types of quadratic elements are used, namely the S8R and STRI65 elements, which stand for 8-node shell elements with reduced integration and a 6-node triangular shell elements 


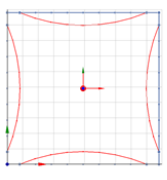

a)

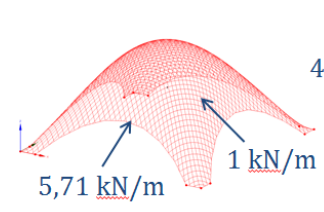

b)

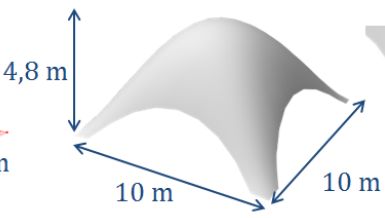

c)

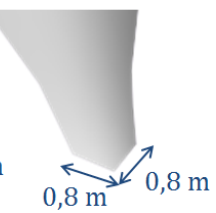

d)

Figure 5: a) flat initial grid in Easy software, b) form found structure with force densities in membrane and boundary cable, c) continuous shell and d) corners of $0,8 \mathrm{~m}$ to exclude stress concentrations.

respectively. Mostly the S8R elements are used, but if (locally) the geometry of the shell does not allow them, STRI65 elements are used instead. Three integration points over one material layer are used through the Sympson integration.

\subsection{Material properties and hypotheses}

The structural feasibility of TRC as formwork and as tensile reinforcement is studied in this paper. It is the aim to have an idea of the order of magnitude of stresses and deformations to see what is - or is not - possible. To this end the material behaviour of the used TRC composite is assumed to be linear elastic, whereas this behaviour in tension is not linear, as can be seen in Figure 3. The concrete's material behaviour is also assumed linear elastic.

The properties of the used TRC, i.e. Glass Fibre Reinforced Inorganic Phosphate Cement (IPC) are presented in Table 1 (Symbion [7]). The properties of concrete are in first approximation assumed to be those of normal concrete C25/30 according to Eurocode 2: Design of concrete structures - Part 1-1: General rules and rules for buildings (European Committee for Standardisation [8]). The properties used during the calculation are found in Table 2.

Table 1: Properties of glass fiber reinforced inorganic phospate cement.

\begin{tabular}{lccc}
\hline Quantity & Symbol & Value & Unit \\
\hline Density & $\rho$ & 1750 & $\mathrm{~kg} / \mathrm{m}^{2}$ \\
Compressive characteristic strength & $\sigma_{c k}$ & 80 & $\mathrm{MPa}$ \\
Compressive design strength & $\sigma_{c d}$ & 40 & $\mathrm{MPa}$ \\
Tensile characteristic strength & $\sigma_{t k}$ & 40 & $\mathrm{MPa}$ \\
Tensile design strength & $\sigma_{t k}$ & 20 & $\mathrm{MPa}$ \\
Young modulus (stage I) & $E_{c 1}$ & 18 & $\mathrm{GPa}$ \\
Fibre density & $V_{f}$ & 13 & $\%$ \\
Poisson ratio & $v$ & 0,3 & \\
\hline
\end{tabular}


Table 2: Properties of concrete C25/30.

\begin{tabular}{lccc}
\hline Quantity & Symbol & Value & Unit \\
\hline Density & $\rho$ & 2400 & $\mathrm{~kg} / \mathrm{m}^{2}$ \\
Compressive characteristic strength & $f_{c k}$ & 25 & $\mathrm{MPa}$ \\
Compressive design strength & $f_{c d}$ & 14,2 & $\mathrm{MPa}$ \\
Young modulus (stage I) & $E_{c 1}$ & 31,5 & $\mathrm{GPa}$ \\
Poisson ratio & $v$ & 0,2 & \\
\hline
\end{tabular}

\subsection{Analysis of TRC formwork}

This section describes how the necessary TRC thickness for its function as formwork is determined for the synclastic shell assuming a $15 \mathrm{~mm}$ concrete section as the load.

The TRC formwork is divided into parts, whose dimensions comply with the Belgian unexceptional transport regulations (Goldstein and Labeeuw [9]), as the formwork can not be transported in one large part of $10 \mathrm{~m}$. The subdivision is done so that a maximum amount of parts with the same geometry is obtained and the moulds for the TRC formwork can be reused; the synclastic shape is divided in a symmetrical way and is supported by different number of vertical supports (Figure 6). For these compositions the necessary TRC thickness to act as formwork is determined.

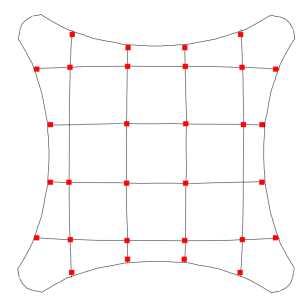

Figure 6: The synclastic shell formwork is divided symmetrically.

After transportation, the TRC formwork parts are assembled on site and supported by vertical supports (red dots Figure 6). The vertical supports are 200 by $200 \mathrm{~mm}$ and are only restricted in the vertical direction (roll in Abaqus). The structure's base edges are hinged. The selfweight of the TRC formwork and the weight of the poured concrete $\left(2400 \mathrm{~kg} / \mathrm{m}^{3} \times\right.$ thickness of concrete) are the only loads working on the formwork structure in this preliminary case study.

When the concrete is poured, the formwork is designed such that the tensile strain $<0,1 \%$ to ensure it remains in the linear elastic part of the TRC composite, 
so the later function of reinforcement is not compromised. Moreover, the displacements of the TRC formwork must not exceed (span between supports)/250 (European Committee for Standardisation [8]) as a formwork structure can only deform very little. Finally, buckling must be checked as it is possibly the deciding factor for slender structures. However, buckling is a complicated phenomenon, therefore a simple approximated method is proposed. Firstly, the linear buckling load of the shell is calculated using the eigenvalue buckling prediction in Abaqus, disregarding any imperfections and assuming a linear elastic material. This value is modified by an imperfection sensitivity factor $\alpha_{i m p}$ obtained from the graphs composed in (Tomás and Tovar [10]) and a safety factor (Medwadowski [11]). The buckling design load $p_{\text {buckle }}$ is then defined using formula (1):

$$
p_{\text {buckle }}=\frac{\alpha_{i m p} \cdot p_{c r}}{\gamma}
$$

With

$$
\begin{array}{ll}
\gamma & \text { safety factor }(3,5) \\
p_{c r} & \text { linear buckling load } \\
\alpha_{i m p} & \text { imperfection sensitivity factor }
\end{array}
$$

The needed thickness of TRC formwork is that one which stays below the requirements of strain (and thus stress), deformations and buckling.

Table 3 shows the results of the TRC formwork for the synclastic shell with different number of supports and the load of the poured concrete $(15 \mathrm{~mm})$. $\epsilon$ represents the maximal strain in the formwork, $U$ the maximal deformation between two spans and $\lambda$ the eigenvalue for buckling reduced by the imperfection sensitivity factor $\alpha_{i m p}$ and the safety factor $\gamma$. For 21 supports $(3 \times 3$ internal supports over the surface and 3 at each edge), $10 \mathrm{~mm}$ of TRC formwork is needed. Increasing the number of supports to $32(4 \times 4$ internal supports and 4 at each edge), decreases the necessary thickness to $8,5 \mathrm{~mm}$ formwork. The edges are critical because local buckling appears (Figure 7). For this reason the number of supports at the edges are increased, namely for 33 supports $(3 \times 3$ internal supports, 5 at each edge and 1 extra in the corners), the necessary thickness is $7 \mathrm{~mm}$. When the 5 supports at the edges remain but the internal supports over the surface are reduced to 5 supports (total of 25 supports), 7,5 $\mathrm{mm}$ is needed.

For all compositions in this shell geometry, it is local buckling of the edges which defines the TRC thickness and not the other intermediate supports. For his reason, the analysis is also done when the whole edge is vertically supported by a beam. When the whole edge is supported, only 4,5 $\mathrm{mm}$ of TRC formwork is needed. The formwork thickness is strongly reduced by supporting the whole edge, however local buckling - now in the corners - is still the determining factor. One could take a step further by thickening for example these corners. 


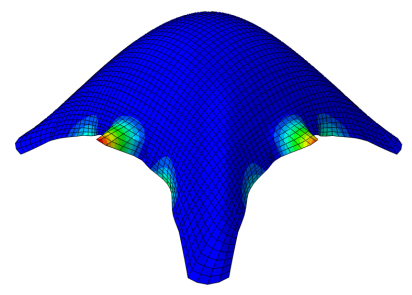

Figure 7: The formwork buckles locally at the edges.

Table 3: More supports at the edges decreases the thickness.

\begin{tabular}{|c|c|c|c|c|c|c|}
\hline $\begin{array}{l}\text { \# supports } \\
\text { total }\end{array}$ & $\begin{array}{l}\text { \# supports } \\
\text { per edge }\end{array}$ & $\begin{array}{c}\text { span supports } \\
{[\mathrm{m}]}\end{array}$ & $\begin{array}{l}\text { TRC } \\
{[\mathrm{mm}]}\end{array}$ & $\begin{array}{c}\epsilon \\
{[\%]}\end{array}$ & $\begin{array}{c}\mathrm{U} \\
{[\mathrm{mm}]}\end{array}$ & $\begin{array}{l}\lambda \\
{[]}\end{array}$ \\
\hline 21 & 3 & 2,5 & 10 & 0,04 & 4,24 & 1,05 \\
\hline 32 & 4 & 2 & 8,5 & 0,05 & 4,32 & 1,13 \\
\hline 33 & 5 & 1,5 & 7 & 0,06 & 3,78 & 1,03 \\
\hline 25 & 5 & 2 & 7,5 & 0,07 & 2,89 & 1,17 \\
\hline 5 & continuous beam & 2 & 4,5 & 0,08 & 1,42 & 1,04 \\
\hline
\end{tabular}

\subsection{Analysis of TRC reinforcement}

This section describes how to determine the TRC thickness needed as tensile reinforcement for the synclastic shell with a concrete section of $15 \mathrm{~mm}$.

Analysing TRC as tensile reinforcement for the concrete shells, all load cases and load combinations, which must be taken into account according to Eurocode 1: Actions on Structures (European Committee for Standardisation [12]) are regarded. The considered load cases are self weight, wind, snow and service loads and the considered load combinations are the Ultimate Limit State and the Serviceability Limit State combinations.

Under all load combinations tensile stresses are obviously present at the top and bottom surface of the concrete shell. Therefore reinforcement is needed on both sides of the shell. In the study presented this paper the reinforcement is realised by placing a TRC layer not only at the bottom but also at the top of the section, i.e. creating a symmetrical section. In this way the possibilities of concrete without additional fibres are studied.

To determine the thickness of the TRC reinforcement, we developed an iterative method, in which the bending moments define the TRC thickness. The steps of the method are described below:

1. The maximum bending moment $M_{D}$ in the shell section is determined with FE for every load combination; 
2. The equilibrium equations for the cross section are solved and gives the thickness $t$ of the TRC reinforcement to withstand $M_{D}$;

3. $M_{D}$ is recalculated when the TRC thickness $t$ is added;

4. The equilibrium equations for the new concrete-TRC section are again solved and give the new thickness $t$ of the TRC;

5. Steps 3 and 4 are repeated until convergence is reached, for the practical execution the TRC thickness $t$ is rounded up to $0,5 \mathrm{~mm}$;

6. Stresses, deformations and buckling load of the shell structure are checked.

When solving the equilibrium equations of the section, following hypotheses are made (European Committee for Standardisation [8]);

- Hypothesis of Bernoulli, i.e. plane cross sections remain plane;

- The bond between concrete and TRC is assumed to be perfect (identic strains);

- The compressive stresses of concrete are determined from the parabolarectangle stress-strain diagram;

- The tensile strength of concrete is neglected;

- TRC is assumed to be linear in this study, the limit strains are therefore $1,1 \%$ oo in tension and $2,2 \%$ in compression.

Table 4 shows the maximum bending moment in the concrete section under the worst load combinations. The synclastic shape with a section of $15 \mathrm{~mm}$ of concrete is subjected to a maximum bending moment of $656,8 \mathrm{Nm} / \mathrm{m}$ under the worst load combination self weight $\times 1,35+$ Point load at edge $\times 1,50$. After iterating, 2,5 $\mathrm{mm}$ of TRC reinforcement is needed on top and bottom surface of the shell. When recalculating the maximum bending moment for the TRC reinforced concrete section it increases to $690,4 \mathrm{Nm} / \mathrm{m}$. The maximum deformation of 5,91 $\mathrm{mm}$ is small and buckling will not occur (eigenvalue of 1,33). The compressive stresses of concrete and TRC equal 3,72 $\mathrm{MPa}$ and 8,35 $\mathrm{MPa}$ respectively and do not constitute any problem.

When designing a concrete section, there is a minimum of tensile reinforcement needed in a concrete section according to Eurocode 2 (European Committee for Standardisation [8]). These recommendations are defined for steel reinforced sections and are adapted in this paper to the equivalent TRC area to have a lower limit of the reinforcement:

$$
A_{s, \min }=0,26 \cdot \frac{f_{c t m}}{f_{T R C}} \cdot b_{t} \cdot d
$$

Following formula (2) for a $15 \mathrm{~mm}$ concrete section, at least $0,5 \mathrm{~mm}$ TRC reinforcement is needed, which is indeed the case for the synclastic shell. As seen in these results, only a few millimeters of reinforcement is needed on top and bottom surface, which indicates promising capacities of TRC as tensile reinforcement for this shell. 
Table 4: Results of the concrete shell and the reinforcement.

\begin{tabular}{l|c}
\hline $\begin{array}{l}\text { Bending moment under the } \\
\text { worst load combination }\end{array}$ & $656,8 \mathrm{Nm} / \mathrm{m}$ \\
\hline TRC reinforcement $t$ & $\mathbf{2 , 5} \mathbf{~ m m}$ \\
\hline Bending moment $M_{D}$ & $690,4 \mathrm{Nm} / \mathrm{m}$ \\
Deformation $U$ & $5,91 \mathrm{~mm}$ \\
Eigenvalue $\lambda$ & 1,33 \\
Compressive stress concrete & $3,72 \mathrm{MPa}$ \\
Compressive stress TRC & $8,35 \mathrm{MPa}$ \\
Tensile stress TRC & $20 \mathrm{MPa}$ \\
\hline
\end{tabular}

\section{Conclusions}

Comparing the performed numerical analysis on TRC formwork and reinforcement of the studied concrete shell, the formwork phase is obviously determining for the minimum thickness of the TRC layer. More specific, local buckling of the edges of the TRC formwork defines the dimensions. Increasing the number of supports at the edges decreases the needed TRC thickness (from $10 \mathrm{~mm}$ for 3 supports at the edges to $7,5 \mathrm{~mm}$ for 5 supports). If the whole edge of the formwork is supported, local buckling of the edge is eliminated - now local buckling of the corners is determining - and 4,5 mm TRC is needed. An explanation for this sensitivity of the edges can be found in the method with which the shell shaped was form found. The geometry was form found under vertical distributed loading with the edges represented by boundary cables with higher stiffness than the rest of the shell. This higher stiffness is not taken into account when the thickness of the formwork is determined, or in other words these edges are a weaker point. This explains why supporting the edges more, gives a better result.

For the TRC to act as reinforcement, only $2,5 \mathrm{~mm}$ is needed on top and bottom surface of the synclastic shell, which proves the promising structural character of the TRC, which is in first place used as formwork. The good mechanical behaviour of the TRC layer, is an additional advantage over its other beneficial properties such as not limiting the curvature of the shell and not corroding like traditional steel reinforcement.

Because the formwork stage determines the minimum TRC thickness, it is questionable if a symmetric TRC-concrete section is the most optimal solution (as the needed TRC reinforcement is thinner). An asymmetric section, with a TRC layer only at the bottom and alternative reinforcement at the top surface could be considered. For constructing the shell this could be more practical as it is not easy 
to pour concrete between two TRC layers or not beneficial for the adhesion of TRC and concrete to put the top surface later on the concrete.

The results are promising and encouraging to continue the research on TRC composites as formwork and reinforcement. In the future, experiments will be performed on TRC shells to evaluate the models which were developed. In that way they can be adapted, and it will become clear if the non-linear material behaviour has to be incorporated. Further, buckling of TRC shells will be examined, as this was every time the deciding factor in the analysis of the formwork phase and it should be questioned if the same imperfection factors and safety factors can be used as those for concrete shells.

\section{References}

[1] Weilandt, A., Rolex learning center in Lausanne: From conceptual design to execution. Proceedings of the International Association for Shell and Spatial Structures, Valencia, Spain, pp. 640-653, 2009.

[2] Nedcam, Spencer dock bridge Dublin, 2014.

[3] Remy, O. \& Wastiels, J., High performance textile reinforced cements: tensile hardening behaviour and modeling. Proceedings of the International Conference on Challenges for Civil Construction, Porto, Portugal, pp. 51-63, 2008.

[4] EP 0861216 B1, Inorganic Resin Compositions, Their Preparation And Use Thereof.

[5] Cuypers, H. \& Wastiels, J., Thin and strong concrete composites with glass textile reinforcement: Modeling the tensile response. SP-250 Textile Reinforced Concrete, pp. 131-148, 2008.

[6] Remy, O., (ed.) Lightweight Stay-in-Place formwork: a concept for future building applications. Vrije Universiteit Brussel: Brussels, Belgium, 2012.

[7] Symbion, Vubonite, building in the future, 2014.

[8] European Committee for Standardisation, Eurocode 2: Design of concrete structures - Part 1: General rules and rules for buildings. CEN, 2004.

[9] Goldstein, G. \& Labeeuw, G., Handleiding van de Atlas der Reiswegen voor Uitzonderlijk Vervoer en Havenfiches. Federaal Ministerie van Verkeer en Infrastructuur (MVI) - ACI - Directie Wegen, 2001.

[10] Tomás, A. \& Tovar, J.P., The influence of initial geometric imperfections on the buckling load of single and double curvature concrete shells. Computers and Structures, pp. 34-45, 2012.

[11] Medwadowski, S.J., Buckling of concrete shells: An overview. Journal of the International Association for Shell and Spatial Structures, 45(144), pp. 131-148, 2004.

[12] European Committee for Standardisation, Eurocode 1: Actions on Structures. CEN, 2002. 